\title{
Scanning Transmission Electron Microscopy
}

National Cancer Institute

\section{Source}

National Cancer Institute. Scanning Transmission Electron Microscopy. NCI Thesaurus.

Code C21342.

An electron microscopic technique for producing images of a surface by scanning an electron beam over the sample and measuring the electronic interactions at the interface. This technique provides highly magnified images of surface morphology. 